central regions with a relatively nutrient rich inflow of Atlantic water, a mixed region in the southern North Sea with a poor inflow of Channel water, and turbid narrow coastal zones with inflow of nutrient rich river water. Plankton studies reveal that the primary production starts early, in February, in the southern region, but is delayed in the coastal zones by turbidity. In stratified areas the algal spring bloom is delayed by mixing towards the greater depth and usually starts with the onset of thermal stratification. The spring bloom soon declines and the algae remain on a low density level in summer, presumably due to depletion of nutrients in the euphotic zone. The coastal zones and the frontal zones between mixed and stratified water have a relatively high summer primary production.

The herbivores (mainly planktonic copepodes and the tunicate Oikopleura dioica) grow and increase in number when the temperature rises and food is available. There is a considerable mismatch with the algal spring bloom, which comes too early and is too short in most regions. The best coincidence occurs in the coastal zones and maybe the frontal zones. Carnivores build high biomasses in late summer and fall in the coastal regions and compete with fish larvae for food and also kill many fish larvae. The large scyphomedusae are most important in this respect.

The overall yearly primary production of the North Sea is estimated to be about $100 \mathrm{mg} \mathrm{C.m-2.} \mathrm{The}$ estimates for herbivores and fish are 20 and $1 \mathrm{mg} \mathrm{C.m}-2$. Considering a growth efficiency of $20 \%$, the herbivores must consume all algae produced. The indication of a low consumption due to bad phenological coincidence in most regions leads to the assumption, that either primary production is underestimated or there is a considerable influx of organic matter from the Atlantic Ocean. During June-July 1979 the carnivore consumption was estimated in the coastal zone of the Southern Bight to be $39 \mathrm{mg} \mathrm{C} . \mathrm{m}^{-2} . \mathrm{d}^{-1}$ at a copepod production of $20 \mathrm{mg} \mathrm{C} \cdot \mathrm{m}^{-2} \cdot \mathrm{d}^{-1}$. Consumption by fish larvae and large jellyfish (Cyanea lamarckii) was $15 \%$ and $74 \%$, respectively.

It seems clear that the productivity of the North Sea depends highly on coastal and frontal zones, where herbivores find sufficient food at optimal growth conditions. Most organic matter will at the end be consumed by invertebrate carnivores, which urge fish populations to reproduce early in spring or to recruit at remote places.

\title{
BREEDING PELAGIC COPEPODS
}

\section{W.C.M. KLEIN BRETELER}

(Netherlands Institute for Sea Research, P.O.Box 59, Texel, the Netherlands).

\section{(SUMMARY)}

A cultivation technique has been developed to breed marine pelagic copepods for experimental purposes. Heterotrophic dinoflagellates occurring in the copepod cultures prevent the cultures from fouling due to sedimentation of autotrophic algae, administered daily from continuous cultures. The dinoflagellates keep themselves well in suspension, consume any excess of algae and dead organic material, and, importantly, appear to be an excellent food for the copepods (KLEIN BRETELER, 1980).

At present Pseudocalanus elongatus, Acartia clausi, Centropages hamatus and Temora longicornis have been bred through 10,11, 33, and 35 filial generations, respectively, and are still breeding continuously. Growth rate and isochronal development were dependent on both the concentration of food and the presence of dinoflagellates.

\section{REFERENCES}

KLEIN BRETELER, Wim C.M., 1980. Continuous breeding of marine pelagic copepods in the presence of heterotrophic dinoflagellates. Mar.Ecol.Progr.Ser., 2:229-233.

\section{A REVIEW OF DATA ON PRODUCTION AND IMPORT OF ORGANIC CARBON IN THE WESTERN WADDEN SEA}

\section{C.C. CADEE}

(Netherlands Institute for Sea Research, P.O.Box 59, Texel, the Netherlands).

\section{(SUMMARY)}

